\title{
Intracellular Leptin-Signaling Pathways in Hypothalamic Neurons: The Emerging Role of Phosphatidylinositol-3 Kinase- Phosphodiesterase-3B-cAMP Pathway
}

\author{
Abhiram Sahu \\ Department of Obstetrics, Gynecology and Reproductive Sciences, and Department of Cell Biology and \\ Physiology, University of Pittsburgh School of Medicine, Magee-Womens Research Institute, Pittsburgh, Pa., USA
}

\section{Key Words}

Leptin $\cdot$ Hypothalamus $\cdot$ Phosphodiesterase-3B $\cdot$ cAMP •

$\mathrm{PI} 3 \mathrm{~K} \cdot \mathrm{STAT} 3 \cdot$ Diet-induced obesity $\cdot$ Leptin resistance

\begin{abstract}
Leptin is secreted primarily by fat cells and acts centrally, particularly in the hypothalamus, to reduce food intake and body weight. Besides the classical JAK2 (Janus kinase-2)STAT3 (signal transducer and activator of transcription-3) pathway, several non-STAT3 pathways play an important role in mediating leptin signaling in the hypothalamus. We have demonstrated that leptin action in the hypothalamus is mediated by an insulin-like signaling pathway involving stimulation of PI3K (phosphatidylinositol-3 kinase) and PDE3B (phosphodiesterase-3B), and reduction in CAMP levels, and that a PI3K-PDE3B-CAMP pathway interacting with the JAK2-STAT3 pathway constitutes a critical component of leptin signaling in the hypothalamus. It appears that defective regulation of multiple signaling pathways in the hypothalamus causes central leptin resistance, a major cause of obesity. In this regard, we have shown that leptin resistance in hypothalamic neurons following chronic central infusion of this hormone is associated with a defect in the PI3KPDE3B-CAMP, and not due to compromised signaling in the JAK2-STAT3 pathway. Similarly, the PI3K, but not the STAT3,
\end{abstract}

pathway is impaired in the hypothalamus during the development of diet-induced obesity. Additionally, our recent work suggests that suppressor of cytokine signaling-3 negatively regulates the PI3K pathway of leptin signaling in the hypothalamus, a mechanism expected to play a significant role in diet-induced obesity. Together, the PI3K-PDE3B-CAMP pathway appears to emerge as a major mechanism of leptin signaling in the hypothalamus in regulating energy balance.

Copyright $\odot 2011$ S. Karger AG, Basel

\section{Introduction}

The maintenance of normal body weight is dependent on the intricate balance between energy intake and energy expenditure. When energy intake is higher than expenditure, the excess energy is stored as fat and continued accumulation of fat ultimately leads to obesity and related disorders. The finding from parabiosis (cross-circulation) experiments in which the normal rats were paired to those with obesity caused by a ventromedial hypothalamic (VMH) lesion showing that control rats ate less and lost weight, led to the idea that some peripheral factor(s) must act at the hypothalamic level to maintain normal energy homeostasis and body weight [1]. In 1994, Jeffrey Friedman's group at the Rockefeller University identified

\section{KARGER}

Fax +4161306 1234

E-Mail karger@karger.ch

www.karger.com (c) 2011 S. Karger AG, Basel

Accessible online at: www.karger.com/nen
Abhiram Sahu

Department of Obstetrics, Gynecology and Reproductive Sciences

University of Pittsburgh School of Medicine, B303 Magee-Womens Research Institute 204 Craft Avenue, Pittsburgh, PA 15213 (USA)

Tel. +1 412641 7669, E-Mail asahu@ pitt.edu 
the gene for one of these factors, the obese gene, and its product leptin, a 16-kd protein - the long-sought satiety factor of adipocyte origin [2].

Leptin signals nutritional status to key regulatory centers in the hypothalamus, and it plays a central role in the regulation of energy homeostasis. Leptin administration centrally or peripherally decreases food intake and body weight in a variety of animals. Importantly, mutations in leptin or its receptor cause obesity in rodents and humans, attesting to the obligatory role of leptin signaling in body weight regulation [3]. Besides its major role in energy homeostasis, leptin is also involved in many other physiological functions including reproduction, growth, bone formation, and cardiovascular and immune regulation $[4,5]$. Most recently, a relationship between leptin and cancer has also been revealed [6]. Importantly, most, if not all, of these functions of leptin are mediated at the level of the hypothalamus. Thus leptin signaling in the hypothalamus, which involves multiple nuclear groups, cell types and signaling pathways, has been the subject of intense research. This review first provides a brief account of leptin target neurons and then focuses on the phosphatidylinositol-3 kinase (PI3K)-phosphodiesterase-3B (PDE3B)-cAMP signaling pathway. Possible mechanisms of central leptin resistance are also discussed.

\section{Leptin-Sensitive Neurons}

After the discovery of leptin, the hypothalamus was promptly established as the major site of leptin action [3, 4]. Accordingly, the long-signaling form of the leptin receptor $(\mathrm{ObRb})$ is highly expressed in various hypothalamic sites including the arcuate nucleus (ARC), $\mathrm{VMH}$, dorsomedial nucleus (DMN), paraventricular nuclei $(\mathrm{PVN})$ and lateral hypothalamic areas $(\mathrm{LH})$; all areas that are implicated in energy homeostasis $[7,8]$. Within the hypothalamus, two sets of neurons residing in the ARC, neuropeptide Y (NPY) neurons coexpressing agoutirelated transcript (AgRP), and proopiomelanocortin (POMC) neurons coexpressing cocaine-amphetaminerelated transcript (CART), appear to be the main leptin targets $[4,9]$. NPY stimulates food intake, and the POMC product, $\alpha$-melanocyte-stimulating hormone $(\alpha-\mathrm{MSH})$, inhibits food intake. AgRP acts as an endogenous antagonist of $\alpha-\mathrm{MSH}$ at central melanocortin receptors, and induces feeding by inhibiting melanocortin $[9,10]$. As might be expected, leptin reduces NPY/AgRP neuronal activity and stimulates that in POMC/CART $[4,9]$. Inter- estingly, leptin action on POMC/CART neurons may involve a reduction of $\gamma$-aminobutyric acid (GABA) and AgRP release from the NPY/AgRP neurons [10]. Leptin also decreases gene expression of other orexigenic neurons such as melanin-concentrating neurons $(\mathrm{MCH})$, galanin (GAL) and orexin, and increases gene expression of anorectic neurons such as neurotensin (NT), corticotrophin-releasing hormone, thyrotrophin-releasing hormone, galanin-like peptide, and brain-derived neurotrophic factor [11]. Furthermore, leptin inhibits the orexigenic action of NPY, MCH and GAL [12], and interacts with prolactin-releasing peptide to reduce food intake [13]. Recent studies also suggest that ObRb-expressing neurons in the VMH (e.g. SF-1-expressing neurons), $\mathrm{DMN}$ and $\mathrm{LH}$ (in addition to $\mathrm{MCH}$ and orexin neurons) mediate leptin action on energy homeostasis [14, 15]. Leptin also decreases food intake by inhibiting the activity of dopamine (DA) neurons in the ventral tegmental area (VTA), possibly via a group of GABAergic LH ObRb-expressing neurons that modify the mesolimbic DA system $[14,16]$. Leptin also activates neurons within the nucleus tractus solitarius $[14,15,17]$. Thus, besides ObRb-expressing neurons in the hypothalamus, those in other regions of the CNS play an important role in mediating leptin action on food intake and body weight regulation.

Leptin also modifies the action of peptides after they have been secreted and alters interactions between orexigenic and anorectic signals to accomplish its role in energy homeostasis. Although the leptin-sensitive neural circuitry that regulates energy homeostasis is complex, a simplistic model for leptin action on hypothalamic signals governing feeding is proposed here (fig. 1). In this model, a decrease in circulating leptin levels during fasting or a deficiency in leptin action due to absence of leptin, leptin receptor mutation or leptin resistance would increase gene expression, peptide release, and actions of orexigenic neural signals, and decrease synthesis and release of anorectic signals resulting in increased food intake. Likewise, increased leptin levels after feeding would inhibit not only the synthesis and release of the orexigenic signals, but it would modify the action of these signals after being released, and stimulate the activity of anorectic signals including their synthesis, release and postsynaptic actions - a net result is the inhibition of food intake. I hypothesize that the acute inhibition of food intake that occurs within an hour of leptin injection may be due to modification of postsynaptic actions of orexigenic and anorectic signals. 
Fig. 1. Schematic presentation of leptin action on hypothalamic signals governing feeding. For details, see the text. NPY = Neuropeptide Y; $\mathrm{MCH}=$ melanin-concentrating hormone; $\mathrm{POMC}=$ proopiomelanocortin; NT $=$ neurotensin [modified from 4].

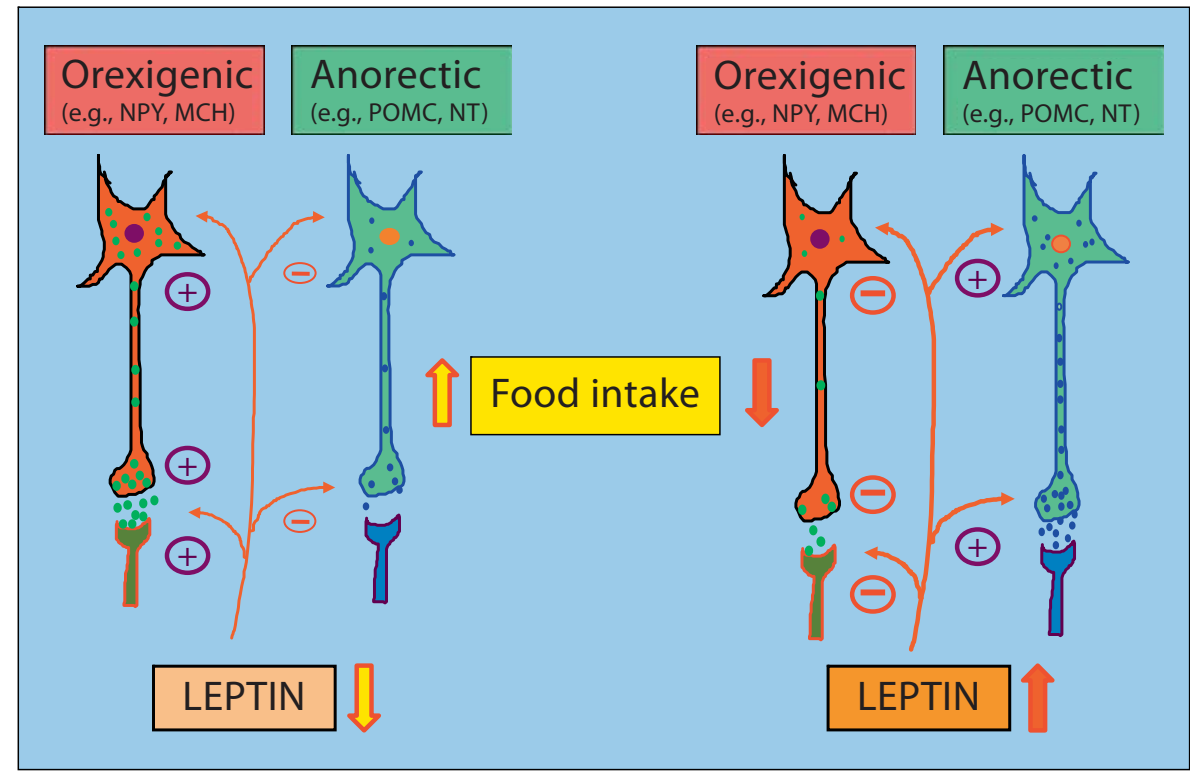

\section{Leptin Signal Transduction Pathways}

The leptin receptor composed of six isoforms is a member of the class 1 cytokine receptor family [18]. The receptor with signaling capacity (ObRb) is highly expressed in most of the leptin target neurons with in the various hypothalamic sites described above [7, 8]. Localized expression of $\mathrm{ObRb}$ in the ARC normalizes most of the abnormalities in $d b / d b$ mice [19]. In contrast, selective loss of ObRb in the ARC or VMN or leptin target neurons of the ARC, such as POMC neurons, and global loss of the receptor in the hypothalamus results in obesity and other metabolic disorders, although the response is milder than that seen in $d b / d b$ mice $[14,15,20]$, suggesting a role of extrahypothalamic ObRb signaling in energy homeostasis. Following the discovery of the leptin receptor, the Janus kinase-2 (JAK2) and signal transducer and activator of transcription (STAT3) pathway was quickly established as a major leptin-signaling pathway in the hypothalamus [3]. Subsequently, several non-STAT3 pathways of leptin signaling in the hypothalamus including the PI3K, PDE3B-cAMP, mammalian target of rapamycin (mTOR), AMP-activated protein kinase (AMPK), and SH-containing protein tyrosine phosphatase-2 (SHP2)-MAPK pathways have been identified [14, 15, 21-23].

\section{JAK2-STAT3 Pathway}

In this signaling pathway, binding of leptin to $\mathrm{ObRb}$ results in receptor dimerization followed by activation and autophosphorylation of JAK2. Activated JAK2 phosphorylates ObRb, which then recruits STAT3. STAT3 becomes phosphorylated, dimerizes and translocates from the cytoplasm to the nucleus where it binds with specific genes such as POMC and NPY/AgRP to regulate their expression. Leptin also stimulates suppressor of cytokine signaling-3 (SOCS3), which acts as a feedback inhibitor of the JAK2-STAT3 pathway. Leptin activates STAT3 in various hypothalamic nuclei including the ARC, VMN, DMN, PVN, LH and pMV regions [24]. A large body of evidence suggests that leptin signaling through STAT3 is critical for maintaining normal energy homeostasis. Thus, brainspecific knockout of STAT3 or deletion of STAT3 binding site in $\mathrm{ObRb}$ in mice causes hyperphagia and morbid obesity $[25,26]$. However, the phenotypes caused by these genetic manipulations are less severe than those of $d b / d b$ animals, suggesting the importance of non-STAT3 pathways in mediating leptin action. Moreover, POMC or AgRPspecific knockout of STAT3 causes mild obesity [27, 28]. Leptin also stimulates STAT5 phosphorylation in the hypothalamus, and STAT5 deletion in the brain causes leptin resistance, hyperphagia and obesity, although to a lesser extent than brain-specific STAT3 deletion [22, 29, 30], suggesting a contribution of the STAT5 pathway in energy homeostasis and body weight regulation. 


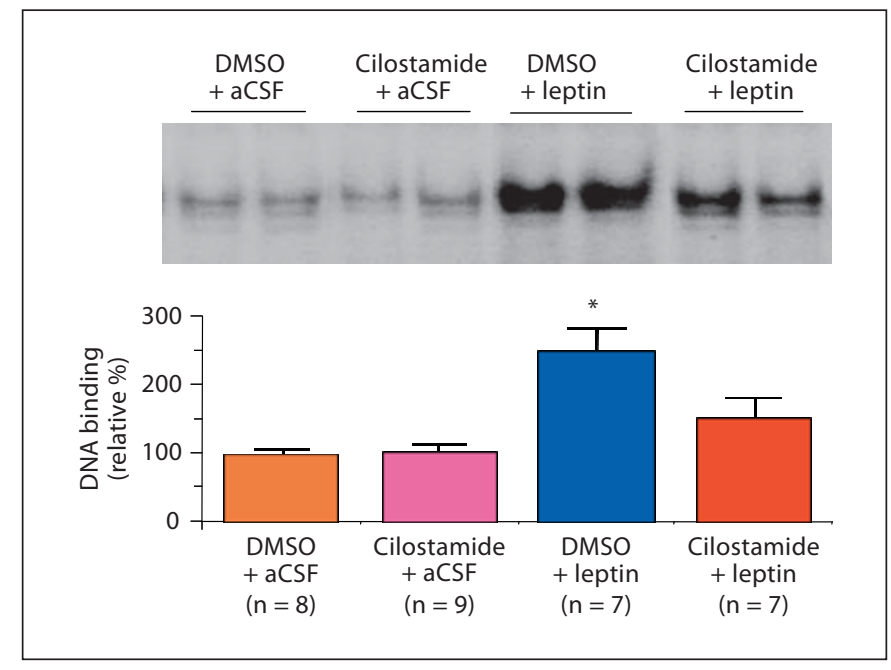

Fig. 2. Cilostamide, a specific PDE3 inhibitor, reverses the effect of leptin on STAT3 activation (DNA binding activity) in the hypothalamus. Fasted $(24 \mathrm{~h})$ rats were injected intracerebroventricularly with DMSO (vehicle for cilostamide) or cilostamide (10 $\mu \mathrm{g})$ followed $30 \mathrm{~min}$ later by leptin $(4 \mu \mathrm{g})$ or artificial cerebrospinal fluid (aCSF, vehicle for leptin). Top: DNA binding activity of STAT3 in the medial basal hypothalamic (MBH) extracts as determined by an electrophoretic mobility shift assay using a ${ }^{32} \mathrm{P}$ labeled M67-SIE oligonucleotide probe. Bottom: results obtained by phosphor imaging and expressed as relative (\%) to vehicle. Data are means \pm SEM for the number of animals in parentheses. * $\mathrm{p}<0.05$ as compared to all other groups. The reversal of STAT3 activation by PDE3B inhibition implies a crosstalk between the JAK2-STAT3 and PDE3B-cAMP pathways in transducing leptin action [modified from 21].

\section{PI3K-PDE3B-cAMP Pathway}

Initial studies in several non-neuronal tissues reported leptin signaling through an insulin-like signaling pathway involving PI3K-dependent activation of PDE3B and eventual reduction of cAMP levels [31, 32]. This information along with the findings that intrahypothalamic cAMP injection increased food intake [33], central injection of dibutyryl cAMP increased hypothalamic levels of NPY [34], and leptin administration modified cAMP response element-mediated gene expression including that in NPY neurons in the hypothalamus [35] led my laboratory to hypothesize that regulation of cAMP levels via activation of PDE3B plays a significant role in mediating leptin action in the hypothalamus in regulation of energy homeostasis. Notably, intracellular cAMP levels are regulated by adenylyl cyclase and cAMP PDEs [31]. Cyclic nucleotide PDEs are a large super family of enzymes consisting of 21 different genes, subgrouped into 11 different families.
PDE3B, one of the two members of the type 3 PDE family of genes, exhibits high affinities for both cAMP and cGMP but prefers cAMP as the substrate [31, 32].

PDE3B was initially identified in adipose tissue and liver but subsequently found in a variety of peripheral tissues and in the CNS $[32,36]$ including the hypothalamic ARC, VMN, DMN, PVN, LH and perifornical hypothalamic areas $[4,36]$. To examine the role of the PDE3B pathway of leptin signaling in the hypothalamus in energy homeostasis, we used a pharmacological approach to interrogate this pathway by cilostamide, which specifically inhibits PDE3 activity [37]. Our demonstration that leptin induces PDE3B activity and reduces cAMP levels in the hypothalamus and that PDE3 inhibition by cilostamide reverses the anorectic and body-weight-reducing effects of leptin, provide evidence for the functional significance in the PDE3B-cAMP pathway of leptin signaling in the hypothalamus [21]. Cilostamide also reverses the leptin-induced STAT3 activation in the hypothalamus suggesting a crosstalk between the PDE3B-cAMP and JAK2-STAT3 pathways (fig. 2) [21]. In addition, PI3K is localized in the ARC [38] and activity of this enzyme is stimulated by leptin $[15,21]$, while PI3K inhibitors reverse the anorectic action of leptin [15]. PI3K signaling is also required for the leptin-induced inhibition of NPY and AgRP neurons [39]. Moreover, PI3K, but not protein kinase $\mathrm{B}$, is an upstream regulator of $\mathrm{PDE} 3 \mathrm{~B}$ in leptin signaling in the hypothalamus [40,41], and $\mathrm{PDE} 3 \mathrm{~B}$ is expressed in ObRb-expressing neurons, including POMC and NPY neurons [42, 43]. Furthermore, cilostamide reverses the leptin-induced POMC and NT gene expression, suggesting leptin action on these neurons is mediated, at least partly, by the PDE3B pathway (fig. 3) [44]. Together, our studies provide evidence indicating that a PI3K-PDE3B-cAMP pathway interacting with the JAK2-STAT3 pathway constitutes a critical component of leptin signaling in the hypothalamus (fig. 4).

One of the areas that requires further investigation is whether these multiple pathways of leptin signaling, such as the JAK2-STAT3 and PI3K-PDE3B-cAMP pathways, become activated in the same leptin-sensitive neurons and if they do, then how it is coordinated during leptin signaling in normal and pathophysiological conditions. Although PDE3B is localized in almost all ObRb-expressing neurons including the POMC and NPY neurons $[42,43]$, it is unknown whether leptin activates PDE3B and decreases cAMP levels, a consequence of PDE3B activation, in all these neurons. Without further technological advancement it would be difficult to examine $\mathrm{PDE} 3 \mathrm{~B}$ and/or cAMP levels in specific neurons in vivo. 


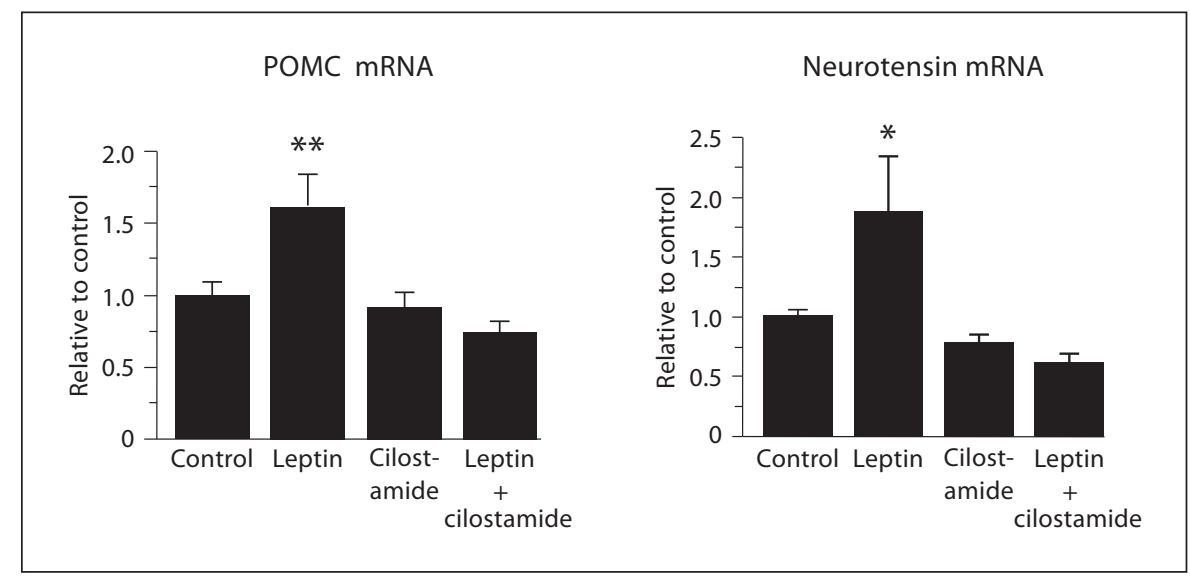

Fig. 3. Cilostamide reverses leptin-induced proopiomelanocortin (POMC) and neurotensin (NT) gene expression as determined by ribonuclease protection assay in the hypothalamus. Rats were injected with cilostamide $(10 \mu \mathrm{g} / 1 \mu \mathrm{l})$ in dimethyl sulfoxide (DMSO) or DMSO alone, and recombinant murine leptin $(4 \mu \mathrm{g} /$ $2 \mu \mathrm{l}$ ) in artificial cerebrospinal fluid (aCSF) or aCSF alone, at 17:00-18:00 h, and food was withdrawn. One hour later, another

On the other hand, the nuclear localization of p-STAT3 has been accepted as an indicator of STAT3 activation in the cell [45], and using this technique leptin has been shown to induce STAT3 activation in various hypothalamic nuclei and specific neurons [22, 24]. Leptin, however, does not activate STAT3 in all ObRb-expressing neurons in the hypothalamus $[22,46]$, and it only activates STAT3 in $\sim 37 \%$ of POMC neurons [47]. Although these findings suggesting that some ObRb-expressing neurons may not utilize the STAT3 pathway, these studies did not address whether STAT3 was expressed in those ObRb-expressing neurons in which leptin failed to activate STAT3. On the other hand, our preliminary finding that all leptin-induced p-STAT3-activated hypothalamic neurons express PDE3B [43] suggests coexistence of these two pathways in the same neuronal populations. Thus, although there is a possibility of differential presence of the STAT3 and PDE3B-cAMP pathways in different leptin-responsive neurons in the hypothalamus, it requires further investigation. In addition, whether the PI3K-PDE3B-cAMP pathway coexists with the other non-STAT3 pathways of leptin signaling in the same hypothalamic neurons remains unknown. Nevertheless, it is likely that depending on individual circumstances, leptin may differentially activate or utilize a specific signaling cascade to fulfill its role in energy homeostasis, and the sequence of activation and/or inactivation of different arms of the leptin signaling in a given neuron may injection of cilostamide or DMSO was given to the rats. After $24 \mathrm{~h}$, a similar injection protocol was used and rats were sacrificed $15 \mathrm{~h}$ after the last injection. Values represent the means \pm SEM. Control (aCSF + DMSO): $\mathrm{n}=4$, leptin: $\mathrm{n}=5$, cilostamide: $\mathrm{n}=5$, and leptin + cilostamide: $\mathrm{n}=7 .{ }^{*} \mathrm{p}<0.05$ and ${ }^{* *} \mathrm{p}<0.01$ vs. all other groups [adapted from 44]. be dependent on the types of environment, such as diet (high fat or low fat) and hypothalamic leptin tone. For example, as discussed below, the PI3K pathway of leptin signaling in the hypothalamus is impaired at the beginning of the diet-induced obesity (DIO) followed by impairment in both the PI3K and STAT3 pathways after the development of DIO in FVB/N mice [48], and the PI3KPDE3B-cAMP pathway but not the STAT3 pathway develops resistance following chronic central leptin infusion, although both pathways become activated during the early part of leptin infusion [49].

Additionally, leptin suppresses ghrelin-induced activation of NPY neurons by the PI3K-PDE3B pathway [50], and blocks glucocorticoid-induced endocannabinoid biosynthesis and suppression of excitation in the PVN via a PDE3B-mediated reduction in cAMP levels [51]. Because the role of ghrelin, glucocorticoid, and endocannabinoids in energy homeostasis is well established $[15,52,53]$, the involvement of PDE3B signaling in mediating leptin's action on these systems further supports a role of the PDE3B pathway in this process. Moreover, several lines of evidence, such as (i) PI3K signaling in the VMN is required for normal energy homeostasis [54], (ii) leptin suppression of white adipose tissue lipogenesis is dependent on hypothalamic PI3K signaling [55], and (iii) PI3K signaling in hypothalamic POMC neurons contributes to the regulation of glucose homeostasis [56], suggest an important role of hypothalamic PI3K signaling in en- 


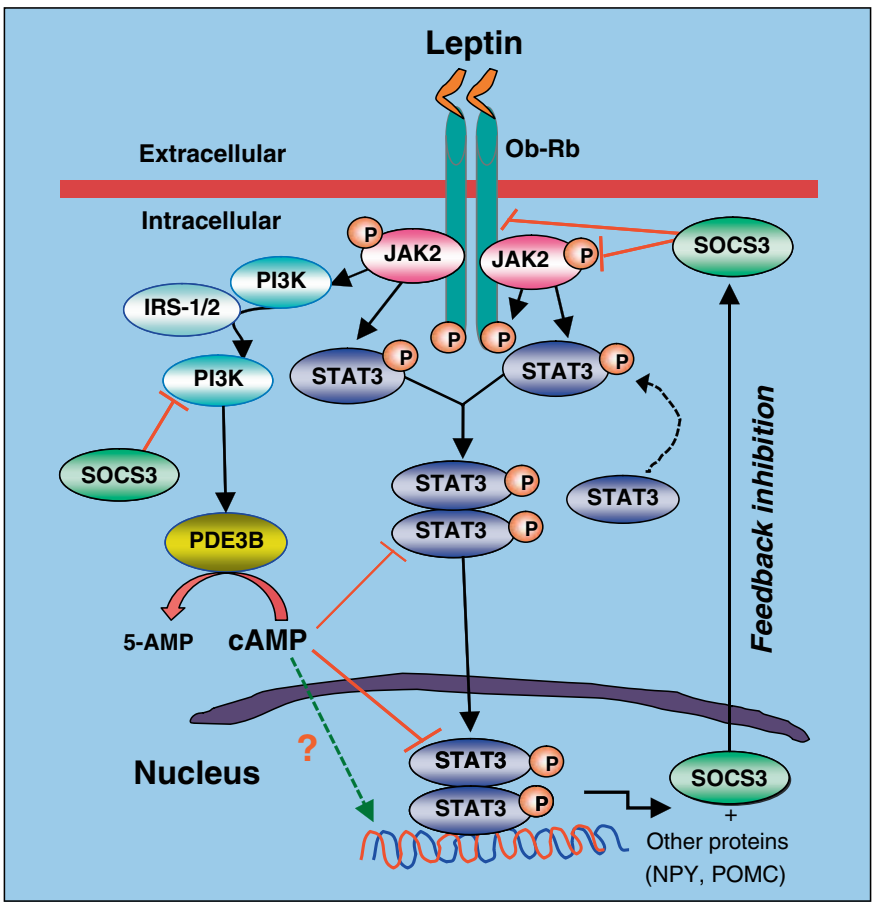

Fig. 4. Schematic of leptin intracellular signaling through the STAT3 and PI3K-PDE3B-cAMP pathways in the hypothalamus. Leptin binding to its receptor $(\mathrm{Ob}-\mathrm{Rb})$ induces activation of JAK2, receptor dimerization, and JAK2-mediated phosphorylation of intracellular part of $\mathrm{Ob}-\mathrm{Rb}$, followed by phosphorylation and activation of STAT3. Activated STAT3 dimerizes and translocates to the nucleus and transactivates target genes including SOCS3, NPY and POMC. Our evidence suggests that leptin also activates PI3K and PDE3B, and reduces cAMP levels. Decrease in cAMP levels appears to be important for STAT3 activation by leptin, because PDE3 inhibition reverses this effect of leptin in the hypothalamus. Also, leptin-induced PDE3B activation-dependent decrease in cAMP levels may directly modify (increase or decrease) expression of POMC, NT, NPY and other genes - a hypothesis needs to be experimentally tested. SOCS3 acts as a negative regulator of both the STAT3 and PI3K pathways of leptin signaling in the hypothalamus, a mechanism that plays a significant role in the development of central leptin resistance and DIO. Other pathways such as SHP2, MAPK/ERK, AMPK, and mTOR pathways and PTP1B that are known to play a role in regulating leptin action and leptin resistance in the hypothalamus have been left out to simplify the figure [modified from 4].

ergy homeostasis. Also, the findings that (i) PI3K signaling in POMC neurons is required for acute suppression of feeding by leptin [57]; (ii) increased PI3K activation due to selective ablation of PIP3 phosphatase (Pten) in ObRb neurons causes lean phenotype [58]; (iii) inactivation of p110 $\beta$ PI3K catalytic subunit in POMC neurons causes central leptin resistance and DIO [59], and (iv) p110 $\beta$ PI3K deletion in AgRP neurons causes leanness, increased leptin sensitivity and resistant to DIO [59], further attest to the role of PI3K signaling in mediating leptin action in hypothalamic neurons.

\section{Leptin Signal Transduction during Central Leptin Resistance}

In the majority of cases, human obesity cannot be attributed to mutations in leptin or its receptor, since obese patients have high circulating leptin levels, and are unresponsive to leptin administration [3, 22, 60]. Rather, a state of leptin resistance is suggested. Whereas a defect in leptin transport may be one of the factors behind the development of leptin resistance in obesity, a large body of evidence suggests that central leptin resistance plays a significant role in the development of obesity [22]. We used two animal models to address the mechanisms of central leptin resistance: a mouse model of DIO and a rat model of chronic central leptin infusion.

\section{Leptin Signaling during the Diet-Induced Obesity}

The rodent model of DIO represents the condition seen in most humans. The findings in DIO rats and mice that (i) the anorectic effect of central leptin is reduced [61, 62], (ii) defects in blood-brain transport are acquired during development of obesity $[63,64]$, and (iii) central leptin gene therapy failed to overcome leptin resistance [65], suggest a significant role of central leptin resistance in DIO. It appears that several intracellular leptin-signaling pathways are impaired during the development of DIO and there are species and strain differences in the sequence of events. In this regard, we demonstrated that the hypothalamic PI3K pathway of leptin signaling was impaired in FVB/N DIO mice fed a high-fat diet (HFD) for 19 or 4 weeks [48], but at the later time point the leptininduced STAT3 activation remained intact in DIO mice (fig. 5). Thus, a defective PI3K pathway may be one of the mechanisms involved in the development of DIO in FVB/N mice. After the development of DIO, the STAT3 pathway also becomes impaired and contributes to the maintenance of DIO on a HFD. Interestingly, the selective defect in the PI3K pathway seen early in the induction of DIO in mice is similar to that seen during the development of central leptin resistance following chronic leptin infusion (see below). Similarly, Martin et al. [66] reported alteration in AMPK but not the STAT3 pathway in $\mathrm{FVB} / \mathrm{N}$ mice on a HFD for 5 weeks. Also, Cota et al. [67] reported alteration in the mTOR pathway without any defect in the STAT3 pathway in DIO rats. Thus, the development of DIO in FVB/N mice in the face of an in- 


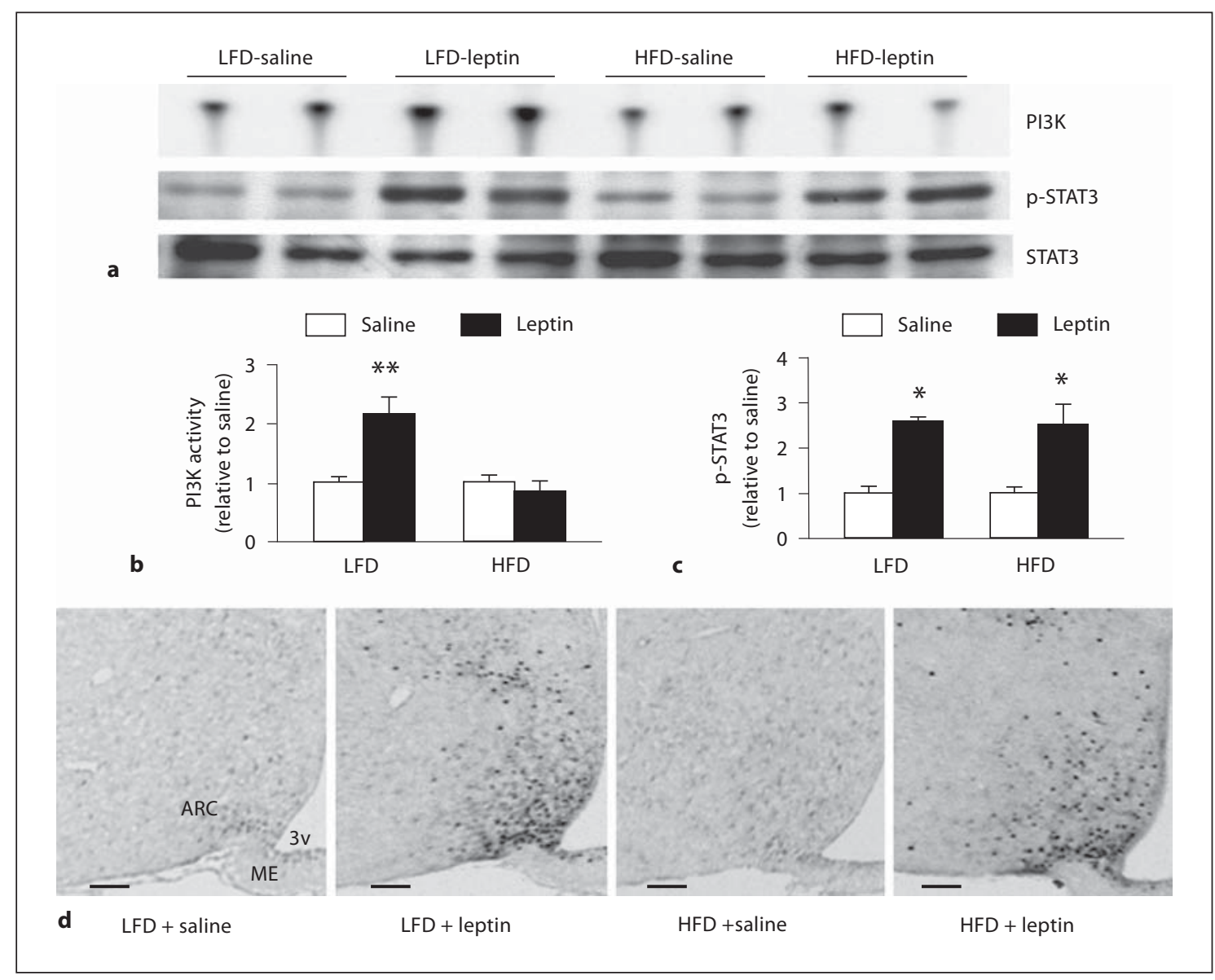

Fig. 5. Leptin failed to increase IRS-1 associated PI3K activity but it increased p-STAT3 in the hypothalamus at 4 weeks on a highfat diet (HFD) in FVB/N mice. Male mice ( $\sim 4$ weeks old) were fed with either a low-fat diet (LFD) or a HFD. Four weeks later, overnight-fasted animals were injected with leptin $(5 \mathrm{mg} / \mathrm{kg}$, i.p.) or saline. PI3K and p-STAT3 were assessed in the hypothalamus after 30 min of injection. a Representative phosphor images obtained from the TLC plate showing PI3P production, an indicator of PI3K activity, as shown. Also shown are p-STAT3 and STAT3 Western blots obtained from the hypothalamic extract used in the PI3K assay. $\mathbf{b}$ Results obtained by phosphor imaging showing the changes in PI3K activity. The values are expressed as relative to the corresponding saline (control) group. ${ }^{* *} \mathrm{p}<0.01$ ( $\mathrm{n}=6$ per group). $\mathbf{c}$ Densitometric analysis of the immunoreactive bands for p-STAT3. The values were first calculated as the ratio of STAT3 and then expressed as relative to the corresponding saline (control) group. ${ }^{*} \mathrm{p}<0.05$ vs. saline group ( $\mathrm{n}=5-6$ per group). $\mathbf{d}$ Representative micrographs of p-STAT3 immunocytochemistry of hypothalamic sections showing leptin-induced increase in $\mathrm{p}$ STAT3-positive cells in both LFD- and HFD-fed mice. Scale bars $=100 \mu \mathrm{m} . \mathrm{ME}=$ Median eminence; $\mathrm{ARC}=$ arcuate nucleus; $3 \mathrm{v}=$ third ventricle [adapted from 48 ]. tact STAT3 pathway suggests that other pathways such as PI3K, AMPK and mTOR play a significant role in the development of obesity in these mice. However, in C57BL/6J mice, both the STAT3 [68] and PI3K [69] pathways are impaired following HFD feeding for 4 weeks.

It also appears that SOCS3 plays a significant role in the development of central leptin resistance and DIO. Thus leptin increases SOCS3 in the hypothalamus [70], DIO increases SOCS3 in the ARC [68], and Socs3 deficiency in the brain [71] or Socs3 haploinsufficiency [72] resists the development of DIO. Although SOCS3 inhibits STAT3 signaling by acting at the level of both JAK2 and ObRb [73], SOCS3 also inhibits the PI3K pathway of leptin signaling in the hypothalamus [74], a potential mechanism of central leptin resistance and DIO.

\section{Leptin Signaling during Chronic Central Leptin Infusion}

Because circulating leptin levels increase within 1 day of HFD feeding [73], exposure of the brain, particularly 
the hypothalamus, to a high level of leptin might contribute to the development of central leptin resistance. In this regard, a recent study has shown that hyperleptinemia is required for the development of leptin resistance [75]. Moreover, in a rat model of chronic central leptin infusion, animals developed resistance to the satiety action of this hormone in association with the development of leptin resistance in NPY, POMC and NT neurons [76, 77]. Interestingly, the PI3K-PDE3B-cAMP pathway of leptin signaling in the hypothalamus was impaired following 16 days of leptin infusion; particularly both PI3K and PDE3B activities were increased and cAMP levels were decreased on day 2 but not day 16 of leptin infusion [49]. In contrast, leptin signaling in the hypothalamus through the JAK2STAT3 pathway remained intact throughout 16 days of leptin infusion despite increased SOCS3 gene expression [78]. These findings suggest a selective leptin resistance in the PI3K-PDE3B-cAMP pathway following increase in hypothalamic leptin tone attained by chronic central infusion of this peptide hormone.

\section{Concluding Remarks}

It is increasingly evident that intracellular signal transduction pathways underlying leptin action in hypothalamic neurons are much more complicated than was originally thought. While the JAK2-STAT3 is one of the major pathways of leptin signaling in the hypothalamus, there are several non-STAT3 pathways, including the PI3K-PDE3B-cAMP, AMPK, mTOR, SH2B and MAPK/ERK that have been shown to play significant role in mediating leptin action in the hypothalamus. Al- though due to the scope of this review I have mainly emphasized on the PI3K-PDE3B-cAMP pathway, the role of the other pathways, including those mentioned here, in hypothalamic action of leptin is obligatory for normal energy homeostasis. Moreover, recent evidence that several extrahypothalamic areas, such as VTA and brainstem, are involved in mediating leptin action, suggests that communication between neurons localized in the various areas must be finely tuned to fulfill the role of leptin in energy homeostasis. In addition, knockdown of any of these pathways in the hypothalamus, alone, does not show such a profound phenotype as $d b / d b$ mice, further suggesting a coordinated involvement of these known and, perhaps, other yet to be discovered signaling pathways for normal function of leptin. Dysregulation of some of these pathways and their interactions in specific neurons could underlie central leptin resistance and contribute to the development of obesity. Although there might be strain differences, it appears that SOCS3 is a major factor for the development of DIO by inhibiting both the STAT3 and PI3K pathways of leptin signaling in the hypothalamus. Finally, the emerging role of PDE3BcAMP signaling in transducing leptin action in the hypothalamus suggests that a defective regulation of this pathway could play a significant role in the development of DIO.

\section{Acknowledgements}

This work was supported by National Institutes of Health Grants DK52844, DK61499 and DK78068. I would like to thank Dr. Tony Plant for critical reading of the manuscript.

\section{References}

1 Hervey GR: The effects of lesions in the hypothalamus in parabiotic rats. J Physiol 1959; 145:336-352.

-2 Zhang Y, Proenca R, Maffei M, Barone M, Leopold L, Friedman JM: Positional cloning of the mouse obese gene and its human homologue. Nature 1994;372:425-432.

3 Friedman JM, Halaas JL: Leptin and the regulation of body weight in mammals. Nature 1998;395:763-770.

4 Sahu A: Leptin signaling in the hypothalamus: emphasis on energy homeostasis and leptin resistance. Front Neuroendocrinol $2003 ; 24: 225-253$
5 Yadav VK, Oury F, Suda N, Liu ZW, Gao XB, Confavreux C, Klemenhagen KC, Tanaka KF, Gingrich JA, Guo XE, Tecott LH, Mann JJ, Hen R, Horvath TL, Karsenty G: A serotonin-dependent mechanism explains the leptin regulation of bone mass, appetite, and energy expenditure. Cell 2009;138:976-989.

6 Cao L, Liu X, Lin EJ, Wang C, Choi EY, Riban V, Lin B, During MJ: Environmental and genetic activation of a brain-adipocyte BDNF/ leptin axis causes cancer remission and inhibition. Cell 2010;142:52-64.

7 Elmquist JK, Bjorbaek C, Ahima RS, Flier JS, Saper CB: Distributions of leptin receptor mRNA isoforms in the rat brain. J Comp Neurol 1998;395:535-547.
8 Caron E, Sachot C, Prevot V, Bouret SG: Distribution of leptin-sensitive cells in the postnatal and adult mouse brain. J Comp Neurol 2010;518:459-476.

-9 Schwartz MW, Woods SC, Porte D Jr, Seeley RJ, Baskin DG: Central nervous system control of food intake. Nature 2000;404:661671.

10 Cone RD: Studies on the physiological functions of the melanocortin system. Endocr Rev 2006;27:736-749.

11 Sahu A: A hypothalamic role in energy balance with special emphasis on leptin. Endocrinology 2004;145:2613-2620. 


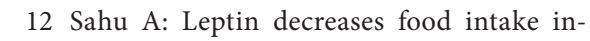
duced by melanin-concentrating hormone, galanin and neuropeptide $\mathrm{Y}$ in the rat. Endocrinology 1998;139:4739-4742.

-13 Ellacott KL, Lawrence CB, Rothwell NJ, Luckman SM: PRL-releasing peptide interacts with leptin to reduce food intake and body weight. Endocrinology 2002;143:368 374.

-14 Myers MG Jr, Munzberg H, Leinninger GM, Leshan RL: The geometry of leptin action in the brain: more complicated than a simple ARC. Cell Metab 2009;9:117-123.

- 15 Morton GJ, Cummings DE, Baskin DG, Barsh GS, Schwartz MW: Central nervous system control of food intake and body weight. Nature 2006;443:289-295.

-16 Leinninger GM, Jo YH, Leshan RL, Louis GW, Yang H, Barrera JG, Wilson H, Opland DM, Faouzi MA, Gong Y, Jones JC, Rhodes CJ, Chua S Jr, Diano S, Horvath TL, Seeley RJ, Becker JB, Munzberg H, Myers MG Jr: Leptin acts via leptin receptor-expressing lateral hypothalamic neurons to modulate the mesolimbic dopamine system and suppress feeding. Cell Metab 2009;10:89-98.

-17 Hayes MR, Skibicka KP, Leichner TM, Guarnieri DJ, DiLeone RJ, Bence KK, Grill HJ: Endogenous leptin signaling in the caudal nucleus tractus solitarius and area postrema is required for energy balance regulation. Cell Metab 2010;11:77-83.

18 Tartaglia LA: The leptin receptor. J Biol Chem 1997;272:6093-6096.

-19 Coppari R, Ichinose M, Lee CE, Pullen AE, Kenny CD, McGovern RA, Tang V, Liu SM, Ludwig T, Chua SC Jr, Lowell BB, Elmquist JK: The hypothalamic arcuate nucleus: a key site for mediating leptin's effects on glucose homeostasis and locomotor activity. Cell Metab 2005;1:63-72.

20 Ring LE, Zeltser LM: Disruption of hypothalamic leptin signaling in mice leads to earlyonset obesity, but physiological adaptations in mature animals stabilize adiposity levels. J Clin Invest 2010;120:2931-2941.

-21 Zhao AZ, Huan JN, Gupta S, Pal R, Sahu A: A phosphatidylinositol 3-kinase phosphodiesterase-3B cyclic AMP pathway in hypothalamic action of leptin on feeding. Nat Neurosci 2002;5:727-728.

-22 Myers MG, Cowley MA, Munzberg H: Mechanisms of leptin action and leptin resistance. Annu Rev Physiol 2008;70:537-556.

-23 Rahmouni K, Sigmund CD, Haynes WG, Mark AL: Hypothalamic ERK mediates the anorectic and thermogenic sympathetic effects of leptin. Diabetes 2009;58:536-542.

24 Hubschle T, Thom E, Watson A, Roth J, Klaus S, Meyerhof W: Leptin-induced nuclear translocation of STAT3 immunoreactivity in hypothalamic nuclei involved in body weight regulation. J Neurosci 2001;21:24132424 .
25 Gao Q, Wolfgang MJ, Neschen S, Morino K, Horvath TL, Shulman GI, Fu XY: Disruption of neural signal transducer and activator of transcription-3 causes obesity, diabetes, infertility, and thermal dysregulation. Proc Natl Acad Sci USA 2004;101:4661-4666.

26 Piper ML, Unger EK, Myers MG Jr, Xu AW: Specific physiological roles for signal transducer and activator of transcription-3 in leptin receptor-expressing neurons. Mol Endocrinol 2008;22:751-759.

27 Gong L, Yao F, Hockman K, Heng HH, Morton GJ, Takeda K, Akira S, Low MJ, Rubinstein M, MacKenzie RG: Signal transducer and activator of transcription-3 is required in hypothalamic agouti-related protein/neuropeptide Y neurons for normal energy homeostasis. Endocrinology 2008;149:33463354.

28 Xu AW, Ste-Marie L, Kaelin CB, Barsh GS: Inactivation of signal transducer and activator of transcription- 3 in proopiomelanocortin (POMC) neurons causes decreased POMC expression, mild obesity, and defects in compensatory refeeding. Endocrinology 2007;148:72-80.

29 Mutze J, Roth J, Gerstberger R, Hubschle T: Nuclear translocation of the transcription factor STAT5 in the rat brain after systemic leptin administration. Neurosci Lett 2007; 417:286-291.

-30 Lee JY, Muenzberg H, Gavrilova O, Reed JA, Berryman D, Villanueva EC, Louis GW, Leinninger GM, Bertuzzi S, Seeley RJ, Robinson GW, Myers MG, Hennighausen L: Loss of cytokine-STAT5 signaling in the CNS and pituitary gland alters energy balance and leads to obesity. PLoS One 2008; 3:e1639.

- 31 Soderling SH, Beavo JA: Regulation of cAMP and cGMP signaling: new phosphodiesterases and new functions. Curr Opin Cell Biol 2000;12:174-179.

32 Bender AT, Beavo JA: Cyclic nucleotide phosphodiesterases: molecular regulation to clinical use. Pharmacol Rev 2006;58:488520.

33 Gillard ER, Khan AM, Ahsan ul H, Grewal RS, Mouradi B, Stanley BG: Stimulation of eating by the second messenger CAMP in the perifornical and lateral hypothalamus. Am J Physiol 1997;273:R107-R112.

- 34 Akabayashi A, Zaia CT, Gabriel SM, Silva I, Cheung WK, Leibowitz SF: Intracerebroventricular injection of dibutyryl cyclic adenosine 3',5'-monophosphate increases hypothalamic levels of neuropeptide Y. Brain Res 1994;660:323-328.

35 Shimizu-Albergine M, Ippolito DL, Beavo JA: Downregulation of fasting-induced cAMP response element-mediated gene induction by leptin in neuropeptide $Y$ neurons of the arcuate nucleus. J Neurosci 2001;21: $1238-1246$
36 Reinhardt RR, Chin E, Zhou J, Taira M, Murata T, Manganiello VC, Bondy CA: Distinctive anatomical patterns of gene expression for cGMP-inhibited cyclic nucleotide phosphodiesterases. J Clin Invest 1995;95:15281538.

37 Beavo JA, Reifsnyder, DH: Primary sequence of cyclic nucleotide phosphodiesterase isozymes and the design of selective inhibitors. Trends Pharmacol Sci 1990;11:150-155.

- 38 Niswender KD, Gallis B, Blevins JE, Corson MA, Schwartz MW, Baskin DG: Immunocytochemical detection of phosphatidylinositol 3-kinase activation by insulin and leptin. J Histochem Cytochem 2003;51:275-283.

-39 Morrison CD, Morton GJ, Niswender KD, Gelling RW, Schwartz MW: Leptin inhibits hypothalamic Npy and Agrp gene expression via a mechanism that requires phosphatidylinositol 3-OH-kinase signaling. Am J Physiol Endocrinol Metab 2005;289:E1051E1057.

40 Sahu A, Metlakunta AR: Evidence suggesting phosphatidylinositol 3-kinase as an upstream regulator of phosphodiesterase-3Bmediated leptin signaling in the hypothalamus. Program No. 380.4. 2004 Abstract Viewer/Itinerary Planner. Washington, Society for Neuroscience, 2004.

41 Koshinaka K, Sahu A: Leptin signaling in the hypothalamus does not involve activation of protein kinase $\mathrm{B} / \mathrm{AKT}$ in the rat hypothalamus. Program No. 20.1. 2007 Neuroscience Meeting Planner. San Diego, Society for Neuroscience, 2007.

42 Litvin D, Sahu M, Koshinaka K, Sahu A: Evidence showing phosphodiesterase-3B co-localization in proopiomelanocortin and neuropeptide $\mathrm{Y}$ expressing neurons in the hypothalamus: further insight into leptin signaling. 89th Annual Meeting of the Endocrine Society, Toronto, June $2-5,2007$, abstr P4-4.

43 Sahu A, Sahu M: Leptin receptor expressing neurons co-express phosphodiesterase-3B (PDE3B) and leptin induces STAT3 activation in PDE3B neurons in the hypothalamus: potential mechanism of leptin signaling. Program No. 783.25. 2008 Neuroscience Meeting Planner. Washington, Society for Neuroscience, 2008.

-44 Sahu A: A role of phosphodiesterase-3B pathway in mediating leptin action on proopiomelanocortin and neurotensin neurons in the hypothalamus. Neurosci Lett 2010; 479:18-21.

45 Leonard WJ, O’Shea JJ: Jaks and STATs: biological implications. Annu Rev Immunol 1998;16:293-322.

46 Caron E, Sachot C, Prevot V, Bouret SG: Distribution of leptin-sensitive cells in the postnatal and adult mouse brain. J Comp Neurol 2010;518:459-476. 
-47 Munzburg H, Huo L, Nillni EA, Hollenberg AN, Bjorbaek C: Role of signal transducer and activator of transcription-3 in regulation of hypothalamic proopiomelanocortin gene expression by leptin. Endocrinology 2003;144:2121-2131.

-48 Metlakunta AS, Sahu M, Sahu A: Hypothalamic phosphatidylinositol 3-kinase pathway of leptin signaling is impaired during the development of diet-induced obesity in $\mathrm{FVB} / \mathrm{N}$ mice. Endocrinology 2008;149:1121-1128.

-49 Sahu A, Metlakunta AS: Hypothalamic phosphatidylinositol 3-kinase-phosphodiesterase-3B cyclic AMP pathway of leptin signalling is impaired following chronic central leptin infusion. J Neuroendocrinol 2005;17: 720-726.

50 Kohno D, Nakata M, Maekawa F, Fujiwara K, Maejima Y, Kuramochi M, Shimazaki T, Okano H, Onaka T, Yada T: Leptin suppresses ghrelin-induced activation of neuropeptide $\mathrm{Y}$ neurons in the arcuate nucleus via phosphatidylinositol 3-kinase- and phosphodiesterase 3-mediated pathway. Endocrinology 2007;148:2251-2263.

-51 Malcher-Lopes R, Di S, Marcheselli VS, Weng FJ, Stuart CT, Bazan NG, Tasker JG: Opposing crosstalk between leptin and glucocorticoids rapidly modulates synaptic excitation via endocannabinoid release. J Neurosci 2006;26:6643-6650.

-52 Dallman MF, La Fleur SE, Pecoraro NC, Gomez F, Houshyar H, Akana SF: Glucocorticoids - food intake, abdominal obesity, and wealthy nations in 2004. Endocrinology 2004; 145:2633-2638.

53 Jo YH, Chen YJ, Chua SC Jr, Talmage DA, Role LW: Integration of endocannabinoid and leptin signaling in an appetite-related neural circuit. Neuron 2005;48:1055-1066.

\54 Xu Y, Hill JW, Fukuda M, Gautron L, Sohn JW, Kim KW, Lee CE, Choi MJ, Lauzon DA, Dhillon H, Lowell BB, Zigman JM, Zhao JJ, Elmquist JK: PI3K signaling in the ventromedial hypothalamic nucleus is required for normal energy homeostasis. Cell Metab 2010;12:88-95.

-55 Buettner C, Muse ED, Cheng A, Chen L, Scherer T, Pocai A, Su K, Cheng B, Li X, Harvey-White J, Schwartz GJ, Kunos G, Rossetti L, Buettner C: Leptin controls adipose tissue lipogenesis via central, STAT3-independent mechanisms. Nat Med 2008;14:667-675.

- 56 Hill JW, Xu Y, Preitner F, Fukuda M, Cho YR, Luo J, Balthasar N, Coppari R, Cantley LC, Kahn BB, Zhao JJ, Elmquist JK: Phosphatidylinositol 3-kinase signaling in hypothalamic proopiomelanocortin neurons contributes to the regulation of glucose homeostasis. Endocrinology 2009;150:48744882 .
57 Hill JW, Williams KW, Ye C, Luo J, Balthasar N, Coppari R, Cowley MA, Cantley LC, Lowell BB, Elmquist JK: Acute effects of leptin require PI3K signaling in hypothalamic proopiomelanocortin neurons in mice. J Clin Invest 2008;118:1796-1805.

58 Plum L, Rother E, Munzberg H, Wunderlich FT, Morgan DA, Hampel B, Shanabrough M, Janoschek R, Konner AC, Alber J, Suzuki A, Krone W, Horvath TL, Rahmouni K, Bruning JC: Enhanced leptin-stimulated PI3K activation in the CNS promotes white adipose tissue transdifferentiation. Cell Metab 2007;6:431-445.

59 Al-Qassab H, Smith MA, Irvine EE, Guillermet-Guibert J, Claret M, Choudhury AI, Selman C, Piipari K, Clements M, Lingard S, Chandarana K, Bell JD, Barsh GS, Smith AJ, Batterham RL, Ashford ML, Vanhaesebroeck B, Withers DJ: Dominant role of the $\mathrm{p} 110 \beta$ isoform of PI3K over p110 $\alpha$ in energy homeostasis regulation by POMC and AgRP neurons. Cell Metab 2009;10:343-354.

60 Heymsfield SB, Greenberg AS, Fujioka K, Dixon RM, Kushner R, Hunt T, Lubina JA, Patane J, Self B, Hunt P, McCamish M: Recombinant leptin for weight loss in obese and lean adults: a randomized, controlled, doseescalation trial. JAMA 1999;282:1568-1575.

61 Lin S, Thomas TC, Storlien LH, Huang XF: Development of high fat diet-induced obesity and leptin resistance in $\mathrm{C} 57 \mathrm{Bl} / 6 \mathrm{~J}$ mice. Int J Obes Relat Metab Disord 2000;24:639-646.

62 Levin BE, Dunn-Meynell AA: Reduced central leptin sensitivity in rats with diet-induced obesity. Am J Physiol Regul Integr Comp Physiol 2002;283:R941-R948.

63 Levin BE, Dunn-Meynell AA, Banks WA: Obesity-prone rats have normal blood-brain barrier transport but defective central leptin signaling before obesity onset. Am J Physiol Regul Integr Comp Physiol 2004;286:R143R150.

64 Banks WA, Farrell CL: Impaired transport of leptin across the blood-brain barrier in obesity is acquired and reversible. Am J Physiol Endocrinol Metab 2003;285:E10-E15.

65 Wilsey J, Zolotukhin S, Prima V, Scarpace PJ: Central leptin gene therapy fails to overcome leptin resistance associated with dietinduced obesity. Am J Physiol Regul Integr Comp Physiol 2003;285:R1011-R1020.

-66 Martin TL, Alquier T, Asakura K, Furukawa N, Preitner F, Kahn BB: Diet-induced obesity alters AMP kinase activity in hypothalamus and skeletal muscle. J Biol Chem 2006;281: 18933-18941.
67 Cota D, Matter EK, Woods SC, Seeley RJ: The role of hypothalamic mammalian target of rapamycin complex 1 signaling in dietinduced obesity. J Neurosci 2008;28:72027208.

68 Munzberg H, Flier JS, Bjorbaek C: Regionspecific leptin resistance within the hypothalamus of diet-induced obese mice. Endocrinology 2004; 145:4880-4889.

69 Metlakunta AR, Sahu A: Evidence suggesting impaired hypothalamic phosphatidylinositol 3-kinase pathway of leptin signaling during the development of dietinduced obesity in mice. Front Neuroendocrinol 2006;27:10.

70 Bjorbaek C, Elmquist JK, Frantz JD, Shoelson SE, Flier JS: Identification of SOCS-3 as a potential mediator of central leptin resistance. Mol Cell 1998;1:619-625.

-71 Mori H, Hanada R, Hanada T, Aki D, Mashima $\mathrm{R}$, Nishinakamura $\mathrm{H}$, Torisu $\mathrm{T}$, Chien KR, Yasukawa H, Yoshimura A: Socs3 deficiency in the brain elevates leptin sensitivity and confers resistance to diet-induced obesity. Nat Med 2004;10:739-743.

72 Howard JK, Cave BJ, Oksanen LJ, Tzameli I, Bjorbaek C, Flier JS: Enhanced leptin sensitivity and attenuation of diet-induced obesity in mice with haploinsufficiency of Socs3. Nat Med 2004;10:734-738.

73 Ziotopoulou M, Mantzoros CS, Hileman SM, Flier JS: Differential expression of hypothalamic neuropeptides in the early phase of diet-induced obesity in mice. Am J Physiol Endocrinol Metab 2000;279:E838-E845.

74 Sahu A, Metlakunta AR, Sahu M: Suppressor of cytokine signaling-3 interacts with the phosphatidylinositol 3-kinase pathway of leptin signaling in the hypothalamus. Program No. 60.10. 2006 Neuroscience Meeting Planner. Atlanta, Society for Neuroscience, 2006.

75 Knight ZA, Hannan KS, Greenberg ML, Friedman JM: Hyperleptinemia is required for the development of leptin resistance. PLoS ONE 2010;5:e11376.

76 Sahu A: Resistance to the satiety action of leptin following chronic central leptin infusion is associated with the development of leptin resistance in neuropeptide $\mathrm{Y}$ neurones. J Neuroendocrinol 2002;14:796-804.

77 Sahu A: Effects of chronic central leptin infusion on proopiomelanocortin and neurotensin gene expression in the rat hypothalamus. Neurosci Lett 2008;440:125-129.

78 Pal R, Sahu A: Leptin signaling in the hypothalamus during chronic central leptin infusion. Endocrinology 2003;144:3789-3798. 